\title{
Detecting ionospheric TEC perturbations caused by natural hazards using a global network of GPS receivers: The Tohoku case study
}

\author{
A. Komjathy ${ }^{1}$, D. A. Galvan ${ }^{2}$, P. Stephens ${ }^{1 *}$, M. D. Butala ${ }^{1}$, V. Akopian ${ }^{1}$, \\ B. Wilson ${ }^{1}$, O. Verkhoglyadova ${ }^{1}$, A. J. Mannucci ${ }^{1}$, and M. Hickey ${ }^{3}$ \\ ${ }^{1}$ NASA Jet Propulsion Laboratory, California Institute of Technology Pasadena, CA 91109, U.S.A \\ ${ }^{2}$ RAND Corporation, Santa Monica, CA 90401, U.S.A. \\ ${ }^{3}$ Embry-Riddle Aeronautical University, Daytona Beach, FL 32114, U.S.A.
}

(Received December 21, 2011; Revised August 16, 2012; Accepted August 17, 2012; Online published January 28, 2013)

\begin{abstract}
Recent advances in GPS data processing have demonstrated that ground-based GPS receivers are capable of detecting ionospheric TEC perturbations caused by surface-generated Rayleigh, acoustic and gravity waves. There have been a number of publications discussing TEC perturbations immediately following the $M 9.0$ Tohoku earthquake in Japan on March 11, 2011. Most investigators have focused on the ionospheric responses up to a few hours following the earthquake and tsunami. In our research, in addition to March 11, 2011 we investigate global ionospheric TEC perturbations a day before and after the event. We also compare indices of geomagnetic activity on all three days with perturbations in TEC, revealing strong geomagnetic storm conditions that are also apparent in processed GEONET TEC observations. In addition to the traveling ionospheric disturbances (TIDs) produced by the earthquake and tsunami, we also detect "regular" TIDs across Japan about 5 hours following the Tohoku event, concluding these are likely due to geomagnetic activity. The variety of observed TEC perturbations are consistent with tsunami-generated gravity waves, auroral activity, regular TIDs and equatorial fluctuations induced by increased geomagnetic activity. We demonstrate our capabilities to monitor TEC fluctuations using JPL's real-time Global Assimilative Ionospheric Model (GAIM) system. We show that a real-time global TEC monitoring network is able to detect the acoustic and gravity waves generated by the earthquake and tsunami. With additional real-time stations deployed, this new capability has the potential to provide real-time monitoring of TEC perturbations that could potentially serve as a plug-in to enhance existing early warning systems.
\end{abstract}

Key words: Ionosphere, GPS, TEC, tsunami detection, acoustic and gravity waves, data assimilation, real-time monitoring, early warning systems.

\section{Introduction}

Natural hazards, including earthquakes, volcanic eruptions, and tsunamis, have been significant threats to humans throughout recorded history. The Global Positioning System (GPS) satellites have become primary sensors to measure signatures associated with such natural hazards. These signatures typically include GPS-derived seismic deformation measurements, co-seismic vertical displacements. Another way to use GPS observables is to compute the ionospheric total electron content (TEC) in order to detect ionospheric disturbances caused by earthquakes, volcano eruptions, and tsunamis.

Earthquakes are known to generate electron density fluctuations in the ionosphere and TEC variations through atmospheric acoustic and gravity waves (e.g., Yuen et al., 1969; Kelley et al., 1985; Calais and Minster, 1995; Artru et al., 2001, 2005; Dudic et al., 2003; Afraimovich et al., 2004; Astafyeva et al., 2009; Kelley, 2009; Rolland, et al.,

\footnotetext{
*Now at Google Corporation, Santa Monica, CA 90401, U.S.A.
}

Copyright (c) The Society of Geomagnetism and Earth, Planetary and Space Sciences (SGEPSS); The Seismological Society of Japan; The Volcanological Society of Japan; The Geodetic Society of Japan; The Japanese Society for Planetary Sciences; TERRAPUB.

doi:10.5047/eps.2012.08.003
2010, 2011; Galvan et al., 2011, 2012; Karia and Pathak, 2011). There are three types of atmospheric waves typically generated by earthquakes: (1) direct acoustic waves generated near the epicenter; (2) gravity waves generated by a tsunami following large earthquakes; and (3) secondary acoustic waves excited by the Rayleigh surface wave outside the epicenter area (e.g., Heki, 2006). It has been shown that GPS measurements are well suited to monitor ionospheric activity associated with earthquakes both in the epicenter area (i.e., using dense local GPS networks) (e.g., Liu et al., 2011b; Rolland et al., 2011; Galvan et al., 2012) and outside of it (i.e., using global GPS networks) (e.g., Rolland et al., 2010; Galvan et al., 2011; Occhipinti et al., 2011) with sufficient spatial and temporal resolution to infer key properties such as velocity, direction, and magnitude of traveling ionospheric disturbances (TIDs). Investigations of pre-seismic ionospheric disturbances have also gained momentum, and this remains a contested research area (e.g., Liu et al., 2010a, b, 2011a; Sharma et al., 2010; Heki, 2011).

Volcanic eruptions also generate acoustic and gravity waves that can cause TEC perturbations. At ionospheric heights, coupling between neutral particles and free electrons induces electron density fluctuations. TEC fluctuations have previously been used to estimate explosive en- 
ergy of a volcanic eruption (Heki, 2006; Dautermann et al., 2009a, b). Although indirectly, using TEC perturbations is becoming increasingly important because of the lack of other reliable means to quantitatively measure explosive energy release.

Tsunamis have been observed to generate traveling ionospheric disturbances due to internal gravity waves (e.g. Artru et al., 2001, 2005; Tsugawa et al., 2004, 2007a, b; Mai and Kiang, 2009; Rolland et al., 2010; Galvan et al., 2011, 2012). Such TIDs are distinguishable from TIDs caused by other sources (such as geomagnetic activity or tropospheric weather) by the fact that tsunami-driven TIDs match the period, velocity, and propagation direction of the ocean tsunamis causing them. Hickey and Cole (1987), Hickey et al. (2009, 2010) and Occhipinti et al. (2006) studied and modeled extensively the gravity wave propagation in the ionosphere. Hickey et al. (2009) and Galvan et al. $(2011,2012)$ provided evidence that modeled and measured tsunami-generated TEC perturbations are in good agreement. Song (2007) showed that tsunami genesis can also be accurately modeled using high-precision GPS positioning near coastal regions. The rapidly generated model by Song (2007) can be validated with near real-time GPS ionospheric observations to track tsunamis soon after the event has occurred.

Multiple natural hazards can occur in a single event. For instance, the eruption of the Soufrière Hills Volcano at Montserrat in 2003 was accompanied by multiple earthquakes and a small tsunami (Dautermann et al., 2009a). More recently, a magnitude 9.0 earthquake occurred on March 11, 2011 at 05:46:23 Universal Time off the coast of Japan, heavily affecting the northern region of Tohoku, as well as the rest of the nation. The Tohoku quake generated a large tsunami resulting in widespread casualties and destruction along the coast of Japan. The Chilean earthquake of February 27, 2010 and the Samoa earthquake of Sep 29, 2009 caused significant fatalities due to the resulting tsunamis, and the Sumatra tsunami of 2004 took the largest toll of human life on record, with approximately 228,000 casualties attributed to the waves. These tsunamis had a major impact on public consciousness as they made their way across the oceans, affecting distant islands and coasts up to 24 hours after the earthquake.

Towards natural hazards monitoring in real-time. If TEC measurements were available in real time, one practical application would be real-time monitoring of the position and intensity of ionospheric disturbance caused by the earthquakes, tsunamis, or volcano eruptions. Ideally, we could monitor the position of the ionospheric disturbance signature in the ionosphere as it moves across the ocean. (The ionospheric tsunami signature should be approximately colocated over the ocean tsunami, but may slightly lag or even precede the ocean wavefront due to variable bathymetry and the time needed for the gravity wave to reach the ionosphere (e.g., Galvan et al., 2011; Occhipinti et al., 2011).) This, however, assumes that we have an abundance of GPS receivers on coasts and islands in the region we are observing. Japan has one of the most densely populated networks of GPS receivers in the world. The U.S. West Coast is similarly instrumented. Elsewhere in the world GPS receivers are less abundant or the receivers are generally installed for other purposes (such as monitoring the motion of tectonic plates), but they are becoming more and more widespread, guaranteeing that opportunities to observe these traveling ionospheric disturbances will increase over time. The NASA Global Differential GPS network of receivers is a global network that provides real-time streaming of 1-second data. This network has around 130 stations worldwide, and is expected to grow in the future (see http://www.gdgps.net/).

A radio signal from a GPS satellite that is near the local horizon will travel through the ionosphere at distances exceeding $1500 \mathrm{~km}$ from the site continuing on through the lower atmosphere until arriving at the receiver. Any GPS receiver collecting measurements at 10 to 15 degree elevation cutoff angle and assuming a $350 \mathrm{~km}$ ionospheric shell height would have a distance between the receiver and IPP about $1900 \mathrm{~km}$ to $1300 \mathrm{~km}$, correspondingly. The $350 \mathrm{~km}$ shell height may be justified as the primary contribution to the TEC observation comes from the $F$-region peak in electron density, at a typical altitude of 300-400 $\mathrm{km}$. Hence, the geometry of GPS TEC measurements is such that they can potentially observe the tsunami signature from the shore even when the tsunami is hundreds of $\mathrm{km}$ off the coast. This capability would be a significant contribution to current tsunami monitoring systems, which currently rely on tidal gauges, DART system (Deep-ocean Assessment and Recording of Tsunamis) and seafloor bottom pressure recording sensors.

Those in-situ measurements are available only at a limited number of locations, and the instruments themselves are generally more expensive than GPS receivers.

In the present study, we first describe the technique we used to process GPS measurements and detect TEC perturbations caused by natural hazards. We show examples of processed TEC perturbations for the March 11 Tohoku earthquake using a global network of GPS receivers. We show the global signature of the Tohoku-generated TEC perturbations along with other signatures observed on that day and the days before and after: traveling ionospheric disturbances and high-latitude and equatorial disturbances. Subsequently we display our real-time Global Assimilative Ionospheric Model (GAIM) (e.g., Komjathy et al., 2010) results demonstrating TEC perturbations from the Tohoku earthquake visible in the GAIM residuals. With additional real-time GPS stations added to the global network, the real-time GAIM model-based TEC perturbation monitoring could serve as an additional tool for natural hazard monitoring and potentially contribute to early warning systems.

\section{JPL Data Processing Technique}

We used the Jet Propulsion Laboratory's (JPL) PyIono package (a bias-fixing algorithm) to generate high-precision calibrated TEC measurements. Calibrating TEC measurements serves multiple purposes for us including quality checking (QC) of processed data, leveling the phase measurements using pseudoranges and comparing modeled TEC perturbations with measured ones. Obtaining absolute TEC values is useful to understand background conditions for the perturbations. However, we are primarily in- 


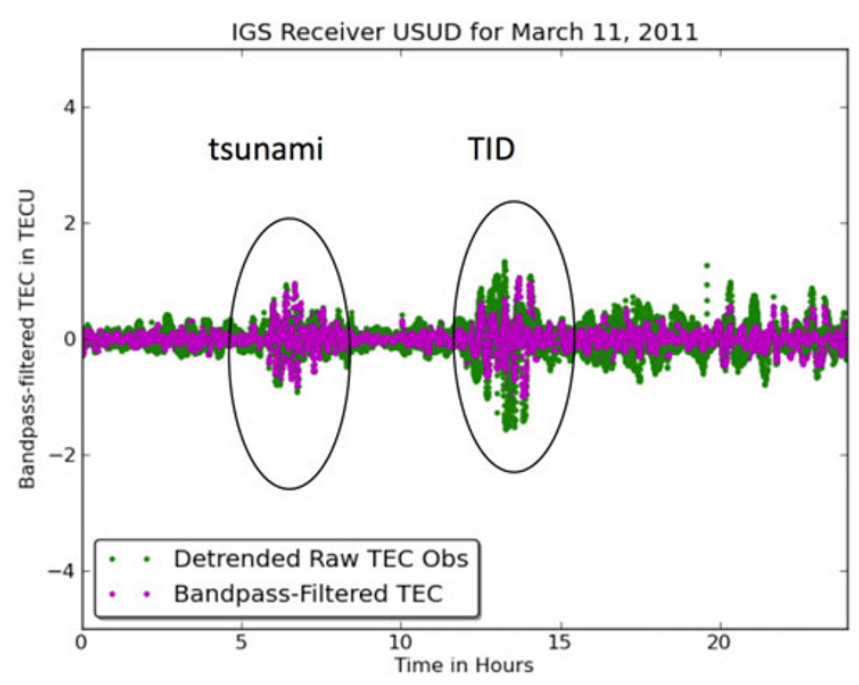

Fig. 1. Measured and band-pass filtered TEC disturbances at Usuda (USUD) on March 11, 2011. The earthquake and tsunami-generated acoustic and gravity waves are shown around UT 6:00 and subsequent TIDs commencing about 5 hours later.

terested in monitoring small-scale variations in ionospheric electron density, hence the changes in TEC are of interest, rather than absolute TEC values. The processing algorithm was first described in Komjathy et al. (2005). We estimate highly precise satellite and receiver interfrequency biases using about 200 GPS receivers distributed worldwide (e.g., Mannucci et al., 1998, 2004). The output of this Kalmanfilter-based least-squares estimation scheme serves as the background ionosphere for the later part of the estimation technique. In the second part of the processing, we use the 200-station-based ionosphere solution to correct measurements from the remaining stations for the ionospheric contribution. In summary, we remove all the unknowns from the observation equation, and subsequently solve for the receiver differential biases directly. The remaining error sources are the multipath and receiver noise contributions, and the ionospheric mapping error (discussed further in Komjathy et al. (2005)).

Subsequently, JPL's PyIono uses TEC observations to compute de-trended TEC data. In addition, a Butterworth band-pass filter (corresponding to waves with periods between 33 and 3.3 minutes ranging between 0.5 and $5 \mathrm{mHz}$ ) is applied to focus on acoustic and gravity wave generated TEC observations. This type of filtering allows us to more easily detect perturbations within an expected range of frequencies, which we can infer from previous observations of tsunami periods, for example. All modules are written in numeric Python for efficient processing of large datasets. It takes approximately 30 minutes to process up to 1200 GPS sites and to generate filtered TEC perturbations. We can use these new capabilities to process data following natural hazards including earthquakes, tsunamis, volcanic eruptions and nuclear weapons tests. In this research we focus on the period of March 10-12, 2011 to demonstrate the detection capabilities. For more details on the process of producing band-pass filtered TEC data, see Galvan et al. (2011, 2012).

\section{Data Processing and Analysis}

We downloaded RINEX data files from the GEONET and IGS networks to perform the following analysis (GEONET, 2011). We used the JPL PyIono package to process 300 GPS stations globally for three days from March 10 to 12, 2011. In Fig. 1, we plot an example for the detrended and band-pass filtered TEC observations at station Usuda (USUD) in Japan to demonstrate the tsunami generated TEC perturbations also reported by other researchers in this EPS Special Issue following the earthquake at UT 5:46 on March 11. In Fig. 1, we also show a traveling ionospheric disturbance (TID) starting about 5 hours later following the earthquake.

In Fig. 2, we show the filtered TEC perturbations as a function of UT and latitude of ionospheric pierce points for the three days. We plotted the filtered TEC for all 300 GPS stations (shown in Fig. 3) at 30-second sampling rate with no averaging applied. In Fig. 2, we collapsed the longitude dimension and plotted TEC perturbations color-coded for all satellites and stations. This was done to maximize the coverage and use all available IGS stations. We plotted the highest TEC perturbation values on the top layer of the figure so as to remain visible and help emphasize values with higher significance. TEC perturbations were plotted at the ionospheric pierce point locations assuming a $300 \mathrm{~km}$ shell height. Magnetic storm main phase (with minimum $D_{\text {st }}$ index $\sim 82$ nT shown in Fig. 2 bottom panel) occurred around 05:00 UT on March 11. We also displayed the Auroral Electrojet $\left(A_{\mathrm{E}}\right)$ Index for the three days. There is clear evidence of disturbed auroral conditions for March 10 and 11 , indicated by the enhanced $A_{\mathrm{E}}$. This is also apparent in the middle panels where the Northern latitude regions show the largest disturbances during March 10 and 11 (disturbed regions circled with red). Equatorial disturbances can also be seen during the three days. The equatorial TEC perturbations are usually present even without storm condition as we routinely see on other days.

The Tohoku earthquake (at $\sim 05: 46$ UT) generated TEC 

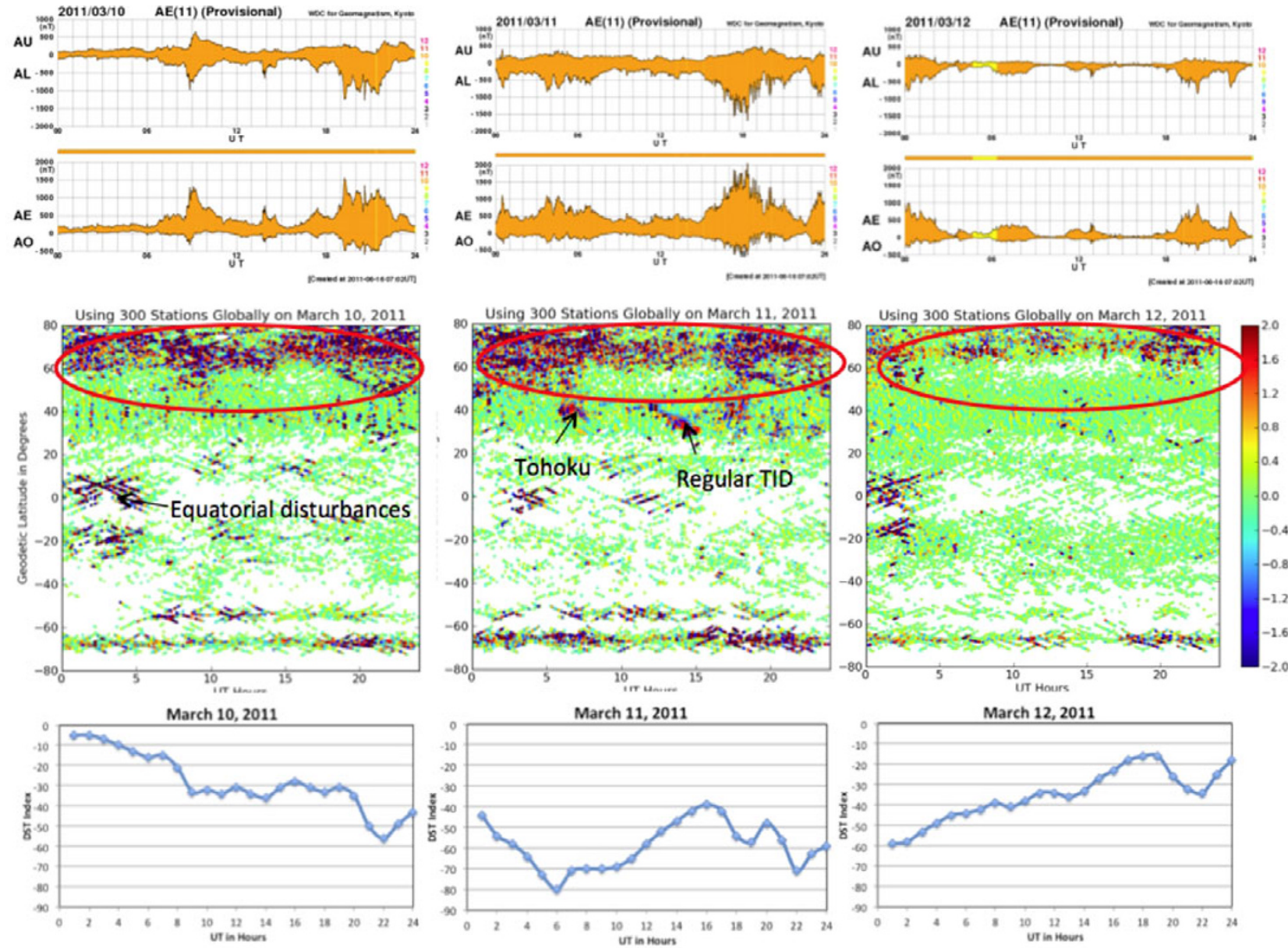

Fig. 2. Ionospheric TEC perturbations for three days on March 10 to 12, 2011 using a global network of GPS receivers. High-latitude ionospheric disturbances are circled. We also show the Tohoku event generated TEC perturbations along with traveling ionospheric disturbances several hours following the event. $A_{\mathrm{E}}$ and $D_{\mathrm{ST}}$ indices also shown for the three consecutive days.

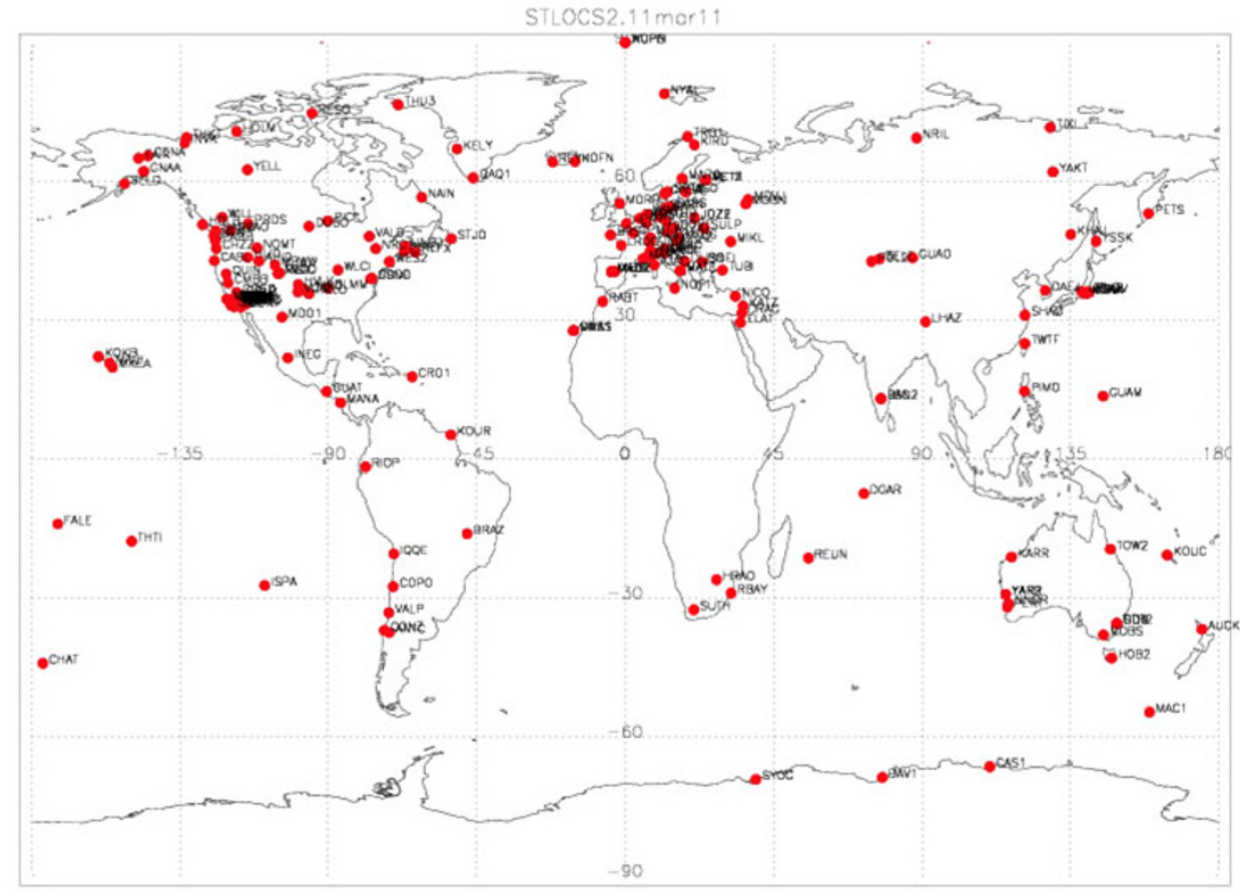

Fig. 3. The global network of GPS receivers used for the March 10 to 12, 2011 data processing. 
signatures shown at around UT 6:00 (Fig. 2, middle panels). There was enhanced geomagnetic activity throughout March 10-11, with a geomagnetic storm main phase occurring within the same hour as the earthquake (between 5 and 6 UT, see Fig. 2, bottom panel) and corresponding to $\sim 1500$ LT at the USUD site. An ionospheric storm (Prölss, 1993 ) induced by geomagnetic activity could cause elevated daytime TEC. By comparing TEC plots around 3-5 UT on March 10th and 11th, we observe the low-latitude daytime signatures between $-20 \mathrm{deg}$ and $20 \mathrm{deg}$ latitude. About five hours after the earthquake, a regular traveling ionospheric disturbance signature is evident, noted with an arrow.

We analyzed the spatial propagation of this TID, observing that it passed over the region of Japan moving from north-to-south, and we therefore concluded it was not related to the earthquake or tsunami, but was most likely a result of the geomagnetic storm depositing energy into the auroral zone via Joule heating, leading to equatorward-moving TIDs (e.g., Richmond and Matsushita, 1975; Nicolls et al., 2004; Galvan et al., 2012). Another possible cause for the TID might be weather-related indicating potential coupling with the lower atmosphere. There are numerous unanswered questions remaining about sources for TIDs caused by ionosphere-atmosphere coupling but we find no reason to conclude that the north-to-south TID was related to the earthquake or tsunami.

Adding the auroral clutter is important in our research as we are attempting to assess how well we can observe these TEC perturbations globally. As seen in Fig. 2, the auroral clutter displays TEC perturbations at similar amplitudes as TIDs, equatorial disturbances and acoustic and gravity wave generated TEC perturbations. As such, the figure demonstrates that our ability to detect perturbations from non-geomagnetic sources is compromised at high latitudes.

\section{Real-Time GAIM Application}

The University of Southern California (USC) and JPL have jointly developed GAIM to monitor space weather, study storm effects, and provide ionospheric calibration for space weather applications. To reveal acoustic and gravity wave-generated TEC disturbances we use the GAIM approach. JPL/USC GAIM is a physics-based 3D data assimilation model that uses both 4DVAR and Kalman filter techniques to solve for the ion and electron density state and key drivers such as equatorial electrodynamics, neutral winds, and ion production terms (e.g., Mannucci et al., 2004; Wang et al., 2004; Mandrake et al., 2005; Pi et al., 2009; Komjathy et al., 2010). GAIM is capable of ingesting multiple data sources, updates the $3 \mathrm{D}$ electron density grid every 5-12 minutes, and solves for improved drivers every $1-2$ hours.

The GAIM forward ionospheric model (based on firstprinciples physics) is a global three-dimensional timedependent model for ion densities. The conservation of mass and momentum equations are solved on an Earth-fixed Eulerian grid (Pi et al., 2003). The volume elements have surfaces parallel to either the magnetic field and potential lines or geomagnetic meridional planes. Using the most recent ionospheric "state" (ion densities in each volume element or voxel) and ionospheric driving forces, the forward model propagates the state to a future time. The observation operator maps the future state to the incoming measurements. These predicted measurement values are differenced from the actual measurements creating an "innovation vector". In the assimilation step, the Kalman filter adjusts the electron densities based on the innovation vector and the prior covariance matrix to compute a statistically minimum variance estimate of the electron density. GAIM residuals are differences between line-of-sight real-time TEC measurements and GAIM-modeled TEC estimates. They are used to distinguish un-modeled ionospheric TEC perturbations such as acoustic and gravity-wave generated TEC perturbations from the modeled TEC background. The Kalman filter works to reduce the residuals in a least squares sense over the entire grid at once, weighted by the uncertainty in each voxel and the uncertainty in the incoming data sources. In the case of the 4DVAR approach, only the driving force parameters are adjusted to produce a least squares estimate of the driving forces as well as electron density (Pi et al., 2003).

JPL has adapted the GAIM system to process groundbased TEC data in near real-time. Calibrated measurements of ionospheric TEC from COSMIC satellites suitable for input into GAIM are also currently made available with latencies between 30 and 120 minutes (Komjathy et al., 2010). Ground GPS receiver networks continue to provide near real-time TEC data from two worldwide networks consisting of $\sim 75$ sites capable of 5-minute latency, and $\sim 125$ additional hourly sites, operated by NASA, JPL and the US Air Force. In this research we show an example of real-time GAIM results obtained on March 11 as the event unfolded.

In Fig. 4, we show the network of streaming and hourly GPS sites from which we currently receive data and subsequently assimilate into the real-time GAIM system. Data from more than 100 sites distributed globally is currently assimilated in real-time. The list and number of sites to assimilate can be much larger and will vary with the application. We use this network of real-time receivers to monitor TEC behavior and ionospheric TEC residuals at individual stations including Usuda, Japan (USUD). Data from USUD is currently assimilated daily into the real-time GAIM system.

Figure 5(A) displays the ionospheric residuals using Global Ionospheric Modeling (GIM) (Komjathy et al., 2005 ) solution. We used about 50 stations near the epicenter to generate the post-processed residuals plot in Fig. 5(A). These are the differences between line-of-sight TEC measurements and GIM-modeled TEC estimates. Note that GIM on the left is strictly a data-driven model. GAIM on the other hand is a physics-based ionospheric model. GAIM TEC residuals in Fig. 5(B) are the differences between lineof-sight TEC measurements and GAIM-modeled TEC estimates. In Fig. 5(B), the GAIM residuals are generated in real-time for the streaming site at Usuda on March 11. All un-modeled effects including acoustic and gravity wave generated TEC perturbations are expected to show in the GAIM TEC residuals. Figure 5(A) has clearly many more observations as we post-processed GEONET data near the epicenter. In Fig. 5(B) we just used station USUD on March 11,2011 as they were coming in to JPL in a real-time oper- 


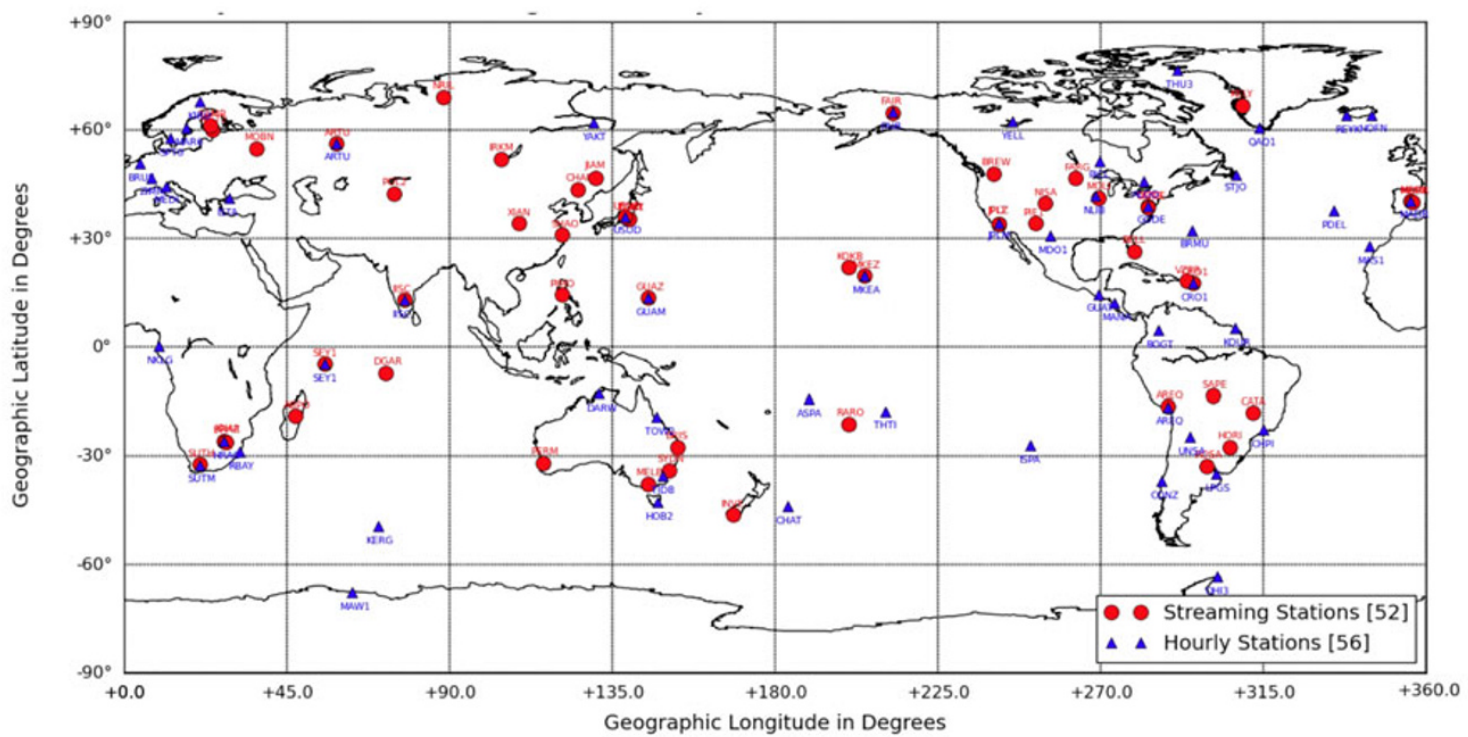

Fig. 4. Streaming and hourly stations (processed simultaneously using the same GAIM algorithm) contributing to the real-time GAIM system on March $11,2011$.
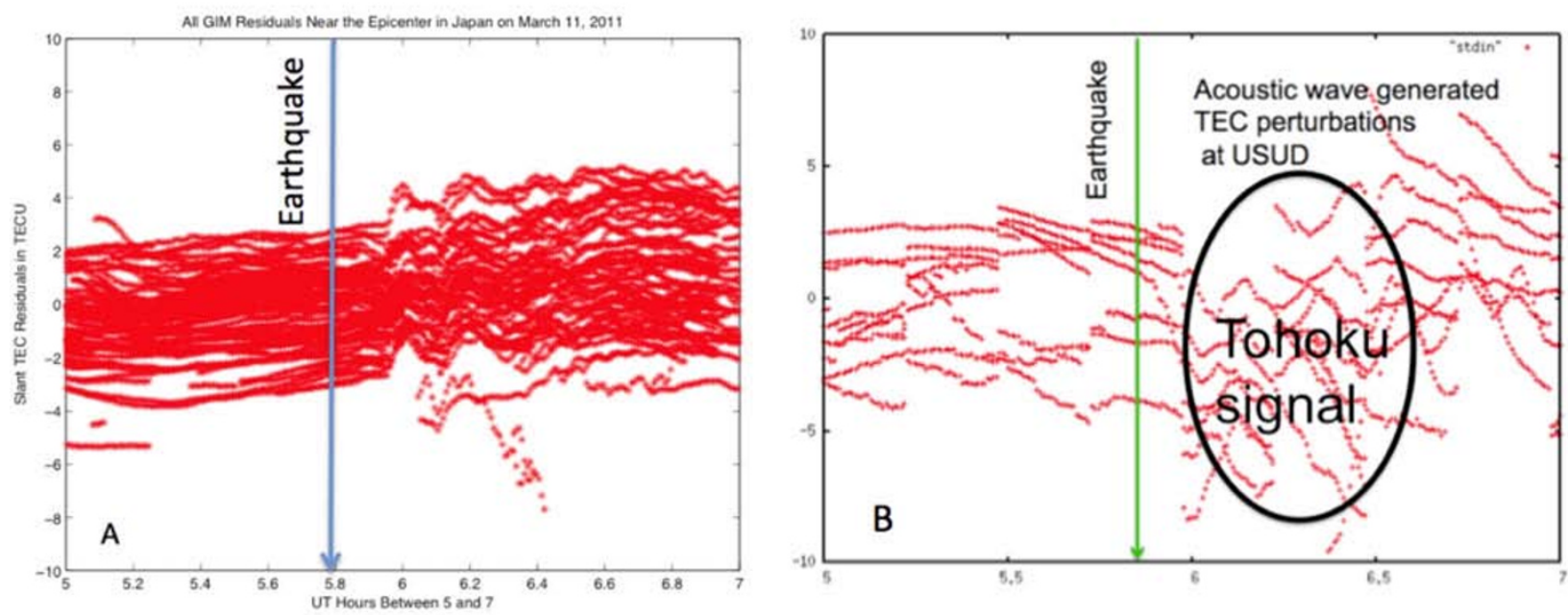

Fig. 5. (A) shows ionospheric TEC residuals using the data driven GIM model and (B) displays real-time TEC residuals using physics-based GAIM model.

ation.

In Fig. 5(A), it is evident that in about 10 minutes following the earthquake the post-processed TEC residuals indicate TEC perturbations that may have been generated by acoustic waves after the earthquake at UT 5:46. It is shown that about 10 minutes after the earthquake the GAIM ionospheric residuals start displaying similar signatures as the post-processed results in Fig. 5(A), caused by the acoustic waves that propagated up to the ionosphere. These signatures seem to be present for all satellites in view. This is the first indication to the best of our knowledge that realtime GAIM processing results will reveal the presence of earthquake generated TEC perturbations.

As the number of real-time GPS monitoring stations increases, we envision that this technology can be used in the near future to detect propagating tsunamis as their ionospheric signatures may be detected about 30 minutes following an earthquake. This could be critical information for existing early warning systems as depending on the geographic locations of earthquake ruptures it may take several hours for fully developed tsunamis to reach populated areas such as Hawaii or California following major earthquakes in the Pacific region.

\section{Conclusions}

We studied ionospheric TEC perturbations caused by earthquake and tsunami generated acoustic and gravity waves in the Tohoku earthquake on March 11, 2011. We demonstrated that global ground-based GPS receivers could be used to monitor such disturbances. One of the main ob- 
jectives of this paper has been to point out the complexities of using a global network of GPS receivers to monitor and detect natural-hazard generated TEC perturbations. To achieve our objective we have processed 300 GPS stations using a global network of GPS receivers displayed in Fig. 3. We used JPL's PyIono package to process the slant TEC observations. Subsequently, we band-pass filtered the slant TEC measurements to generate filtered TEC observations. We showed that using about 300 GPS receivers we are able to map high and low latitude TEC disturbances, traveling ionospheric disturbances and the Tohoku earthquake generated TEC perturbations caused by acoustic and gravity waves. We also showed that March 10 and 11 exhibited disturbed geomagnetic conditions with high-latitude and lowlatitude TEC perturbations. We detected a regular traveling ionospheric disturbance, presumably caused by increased geomagnetic activity, several hours following the Tohoku event.

We demonstrated the JPL real-time GAIM capabilities using about 100 real-time streaming and hourly GPS stations. We showed the real-time GAIM ionospheric residuals at Usuda, Japan demonstrating a signature consistent with an acoustic wave of earthquake origin, suggesting that this technology has a great potential for detecting natural-hazards-generated TEC perturbations including earthquakes and tsunamis. Furthermore, volcanic eruptions and nuclear tests can generate TEC perturbations that may also be detected using the same technology. There is much work remains to be done and on-going developments of this technology will be addressed in forthcoming publications.

Acknowledgments. The authors would like to thank Dr. John LaBrecque of NASA Headquarters and the Earth Science and Interior NASA ROSES Grant (NNH07ZDA001N-ESI), which made this research possible. This research was performed at the Jet Propulsion Laboratory, California Institute of Technology under contract to the National Aeronautics and Space Administration.

\section{References}

Afraimovich, E. L., E. I. Astafieva, and S. V. Voyeikov, Isolated ionospheric disturbances as deduced from global GPS Network, Ann. Geophys., 22, 47-62, 2004.

Artru, J., P. Lognonné, and E. Blanc, Normal modes modelling of postseismic ionospheric oscillations, Geophys. Res. Lett., 28, 697-700, doi:10.1029/2000GL000085, 2001.

Artru, J., V. Ducic, H. Kanamori, P. Lognonné, and M. Murakami, Ionospheric detection of gravity waves induced by tsunamis, Geophys. J. Int., 160, 840-848, doi:10.1111/j.1365-246X.2005.02552.x, 2005.

Astafyeva, E., K. Heki, V. Kiryushkin, E. Afraimovich, and S. Shalimov, Two-mode long-distance propagation of coseismic ionosphere disturbances, J. Geophys. Res., 114, A10307, doi:10.1029/2008JA013853, 2009.

Calais, E. and J. B. Minster, GPS detection of ionospheric perturbations following the January 17, 1994, Northridge earthquake, Geophys. Res. Lett., 22, 1045-1048, doi:10.1029/95GL00168, 1995.

Dautermann, T., E. Calais, and G. S. Mattioli, Global Positioning System detection and energy estimation of the ionospheric wave caused by the 13 July 2003 explosion of the Soufrière Hills Volcano, Montserrat, $J$. Geophys. Res., 114, B02202, doi:10.1029/2008JB005722, 2009a.

Dautermann, T., E. Calais, P. Lognonné, and G. S. Mattioli, Lithosphereatmosphere-ionosphere coupling after the 2003 explosive eruption of the Soufriere Hills Volcano, Montserrat, Geophys. J. Int., 179, 15371546, doi:10.1111/j.1365-246X.2009.04390.x, 2009b.

Ducic, V., J. Artru, and P. Lognonné, Ionospheric remote sensing of the Denali Earthquake Rayleigh surface waves, Geophys. Res. Lett., 30(18), 1951, doi:10.1029/2003GL017812, 2003.

Galvan, D. A., A. Komjathy, M. P. Hickey, and A. J. Mannucci, The
2009 Samoa and 2010 Chile tsunamis as observed in the ionosphere using GPS total electron content, J. Geophys. Res.-Space Physics, 116, A06318, doi:10.1029/2010JA016204, 2011.

Galvan, D. A., A. Komjathy, M. P. Hickey, P. Stephens, J. Snively, Y. Tony Song, M. D. Butala, and A. J. Mannucci, Ionospheric signatures of Tohoku-Oki tsunami of March 11, 2011: Model comparisons near the epicenter, Radio Sci., 2012RS005023, 2012 (in press).

GEONET GPS network information, available at: http://terras.gsi.go.jp/gps/geonet_top.html, 2011.

Heki, K., Explosion energy of the 2004 eruption of the Asama Volcano, central Japan, inferred from ionospheric disturbances, Geophys. Res. Lett., 33, L14303, doi:10.1029/2006GL026249, 2006.

Heki, K., Ionospheric electron enhancement preceding the 2011 Tohoku-Oki earthquake, Geophys. Res. Lett., 38, L17312, doi:10.1029/2011GL047908, 2011.

Hickey, M. P. and K. D. Cole, A quartic dispersion equation for internal gravity waves in the thermosphere, J. Atmos. Terr. Phys., 49, 889-899, 1987.

Hickey, M. P., G. Schubert, and R. L. Walterscheid, Propagation of tsunami-driven gravity waves into the thermosphere and ionosphere, $J$. Geophys. Res., 114, A08304, doi:10.1029/2009JA014105, 2009.

Hickey, M. P., G. Schubert, and R. L. Walterscheid, Atmospheric airglow fluctuations due to a tsunami-driven gravity wave disturbance, J. Geophys. Res., 115, A06308, doi:10.1029/2009JA014977, 2010.

Karia, S. P. and K. N. Pathak, Change in refractivity of the atmosphere and large variation in TEC associated with some earthquakes, observed from GPS receiver, Adv. Space Res., 47(5), 867-876, 2011.

Kelley, M. C., The Earth's Ionosphere: Plasma Physics and Electrodynamics, International Geophysics Series, vol. 96, Elsevier Academic Press, 2009.

Kelley, M. C., R. Livingston, and M. McCready, Large amplitude thermospheric oscillations induced by an earthquake, Geophys. Res. Lett., 12, 577-580, doi:10.1029/GL012i009p00577, 1985.

Komjathy, A., L. Sparks, B. D. Wilson, and A. J. Mannucci, Automated daily processing of more than 1000 ground-based GPS receivers for studying intense ionospheric storms, Radio Sci., 40, RS6006, doi:10.1029/2005RS003279, 2005.

Komjathy, A., B. Wilson, X. Pi, V. Akopian, M. Dumett, B. Iijima, O. Verkhoglyadova, and A. J. Mannucci, JPL/USC GAIM: On the impact of using COSMIC and ground-based GPS measurements to estimate ionospheric parameters, J. Geophys. Res., 115, A02307, doi:10.1029/2009JA014420, 2010.

Liu, J. Y., Y. I. Chen, C. H. Chen, and K. Hattori, Temporal and spatial precursors in the ionospheric global positioning system (GPS) total electron content observed before the 26 December 2004 M9.3 Sumatra-Andaman Earthquake, J. Geophys. Res., 115, A09312, doi:10.1029/2010JA015313, 2010a.

Liu, J. Y., H. F. Tsai, C. H. Lin, M. Kamogawa, Y. I. Chen, C. H. Lin, B. S. Huang, S. B. Yu, and Y. H. Yeh, Coseismic ionospheric disturbances triggered by the Chi-Chi earthquake, J. Geophys. Res., 115, A08303, doi:10.1029/2009JA014943, 2010b.

Liu, J. Y., H. Le, Y. I. Chen, C. H. Chen, L. Liu, W. Wan, Y. Z. Su, Y. Y. Sun, C. H. Lin, and M. Q. Chen, Observations and simulations of seismoionospheric GPS total electron content anomalies before the 12 January 2010 M7 Haiti earthquake, J. Geophys. Res., 116, A04302, doi:10.1029/2010JA015704, 2011a.

Liu, J. Y., C. H. Chen, C. H. Lin, H. F. Tsai, C. H. Chen, and M. Kamogawa, Ionospheric disturbances triggered by the 11 March 2011 M9.0 Tohoku earthquake, J. Geophys. Res., 116, A06319, doi:10.1029/2011JA016761, 2011b.

Mai, C.-L. and J.-F. Kiang, Modeling of ionospheric perturbation by 2004 Sumatra tsunami, Radio Sci., 44, 3011, doi:10.1029/2008RS004060, 2009.

Mandrake, L., B. Wilson, C. Wang, G. Hajj, A. Mannucci, and X. $\mathrm{Pi}$, A performance evaluation of the operational Jet Propulsion Laboratory/University of Southern California Global Assimilation Ionospheric Model (JPL/USC GAIM), J. Geophys. Res., 110, A12306, doi:10.1029/2005JA011170, 2005.

Mannucci, A. J., B. D. Wilson, D. N. Yuan, C. H. Ho, U. J. Lindqwister, and T. F. Runge, A global mapping technique for GPS-derived ionospheric total electron content measurements, Radio Sci., 33, 565-582, doi:10.1029/97RS02707, 1998.

Mannucci, A. J., G. A. Hajj, B. A. Iijima, A. Komjathy, T. K. Meehan, X. Q. Pi, J. Srinivasan, B. T. Tsurutani, B. Wilson, L. D. Zhang, and M. Moldwin, GPS-based remote sensing of the geospace environment: Horizontal and vertical structure of the ionosphere and plasmasphere, 
in Society of Photo-Optical Instrumentation Engineers (SPIE) Conference Series, Society of Photo-Optical Instrumentation Engineers (SPIE) Conference Series, vol. 5660, edited by C. A. Nardell, P. G. Lucey, J.-H. Yee, and J. B. Garvin, pp. 1-13, doi:10.1117/12.580048, 2004.

Nicolls, M. J., M. C. Kelley, A. J. Coster, S. A. González, and J. J. Makela, Imaging the structure of a large-scale TID using ISR and TEC data, Geophys. Res. Lett., 31, 9812, doi:10.1029/2004GL019797, 2004.

Occhipinti, G., P. Lognonné, E. A. Kherani, and H. Hébert, Threedimensional waveform modeling of ionospheric signature induced by the 2004 Sumatra tsunami, Geophys. Res. Lett., 33, L20104, doi:10.1029/2006GL026865, 2006.

Occhipinti, G., P. Coïsson, J. J. Makela, S. Allgeyer, A. Kherani, H. Hébert, and P. Lognonné, Three-dimensional numerical modeling of tsunamirelated internal gravity waves in the Hawaiian atmosphere, Earth Planets Space, 63(7), 847-851, 2011.

Pi, X., C. Wang, G. A. Hajj, G. Rosen, B. D. Wilson, and G. J. Bailey, Estimation of $\mathrm{E} \AA \sim \mathrm{B}$ drift using a global assimilative ionospheric model: An observation system simulation experiment, J. Geophys. Res., 108(A2), 1075, doi:10.1029/2001JA009235, 2003.

Pi, X., A. J. Mannucci, B. A. Iijima, B. D. Wilson, A. Komjathy, T. F. Runge, and V. Akopian, Assimilative modeling of ionospheric disturbances with FORMOSAT-3/COSMIC and ground-based GPS measurements, Terr. Atmos. Ocean. Sci., 20(1), 273-285, 2009.

Prölss, G. W., Common origin of positive ionospheric storms at middle latitudes and the geomagnetic activity effect at low latitudes, J. Geophys. Res., 98, 5981, 1993.

Richmond, A. D. and S. Matsushita, Thermospheric response to a magnetic substorm, J. Geophys. Res., 80, 2839-2850, doi:10.1029/JA080i019p02839, 1975.

Rolland, L. M., G. Occhipinti, P. Lognonné, and A. Loevenbruck, Ionospheric gravity waves detected offshore Hawaii after tsunamis, Geophys. Res. Lett., 37, 17,101, doi:10.1029/2010GL044479, 2010.

Rolland, L., P. Lognonne, and H. Munekane, Detection and modeling of
Rayleigh waves induced patterns in the ionosphere, J. Geophys. Res.Space Physics, doi:10.1029/2010JA016060, 2011 (in press).

Sharma, K., R. S. Dabas, S. K. Sarkar, R. M. Das, S. Ravindran, and A. K. Gwal, Anomalous enhancement of ionospheric F2 layer critical frequency and total electron content over low latitudes before three recent major earthquakes in China, J. Geophys. Res., 115, A11313, doi:10.1029/2009JA014842, 2010.

Song, Y. T., Detecting tsunami genesis and scales directly from coastal GPS stations, Geophys. Res. Lett., 34, L19602, doi:10.1029/2007GL031681, 2007.

Tsugawa, T., A. Saito, and U. Otsuka, A statistical study of large-scale traveling ionospheric disturbances using the GPS network in Japan, $J$. Geophys. Res., 109(A6), A06302, doi:10.1029/2003JA010302, 2004.

Tsugawa, T., Y. Otsuka, A. J. Coster, and A. Saito, Medium-scale traveling ionospheric disturbances detected with dense and wide TEC maps over North America, Geophys. Res. Lett., 34, L22101, doi:10.1029/2007GL031663, 2007a.

Tsugawa, T., N. Kotake, Y. Otsuka, and A. Saito, Medium-scale traveling ionospheric disturbances observed by GPS receiver network in Japan: A short review, GPS Solut., 11(2), 139-144, doi:10.1007/s10291-00600455, 2007b.

Wang, C., G. Hajj, X. Pi, I. G. Rosen, and B. Wilson, Development of the global assimilative ionospheric model, Radio Sci., 39, RS1S06, doi:10.1029/2002RS002854, 2004.

Yuen, P. C., P. F. Weaver, and R. K. Suzuki, Continuous, traveling coupling between seismic waves and the ionosphere evident in May 1968 Japan earthquake data, J. Geophys. Res., 74, 2256-2264, 1969.

A. Komjathy (e-mail: attila.komjathy@jpl.nasa.gov), D. A. Galvan, P. Stephens, M. D. Butala, V. Akopian, B. Wilson, O. Verkhoglyadova, A. J. Mannucci, and M. Hickey 